\title{
CS modality effects in one-trial backward and forward excitatory conditioning as assessed by conditioned suppression of licking in rats
}

\author{
FIA VAN WILLIGEN, JAMES EMMETT, DAVID COTE, and JOHN J. B. AYRES \\ University of Massachusetts, Amherst, Massachusetts
}

\begin{abstract}
Rats received a single 4-sec 1-mA grid-shock US either preceded or followed by a 4-sec tone or light CS. Conditioning was later assessed by comparing the amount of lick suppression evoked by the forward- or backward-paired CS versus an explicitly unpaired CS. The backward-paired CS produced more suppression than the unpaired CS only when both were tone; the light evoked strong suppression whether paired or not. In the forward procedure, tone produced more suppression when paired and less when unpaired than did light; conditioning thus appeared stronger with the tone. In one experiment, observations showed that rats froze during the forward-paired tone but not during the light. Increasing CS duration from 4 to $12 \mathrm{sec}$ had no effect for the forwardpaired light but increased freezing to the forward-paired tone. Another experiment showed similar unconditioned suppression to tone and light but faster habituation to tone. Problems that these results create for interpreting evidence for excitatory backward conditioning in the conditioned suppression procedure are discussed.
\end{abstract}

The lick-suppression technique (R. C. Leaf \& S. R. P. Leaf, 1966; R. C. Leaf \& Muller, 1965; Vogel \& Spear, 1966) has become a popular tool for the study of aversive emotional conditioning with rats. With this technique, a conditioned stimulus (CS), such as a tone, is paired with an aversive unconditioned stimulus (US), such as an electric shock. Later, the CS is presented while the rat is licking a water tube, and the degree to which the CS disrupts the licking is taken as a measure of the CS's conditioned strength.

Given the large number of studies in the licksuppression literature, it is curious that there are only a few that have shown conditioning to a light CS after many CS-US pairings (e.g., Kasprow, Cacheiro, Balaz, \& Miller, 1982), and only one that we know of claims to have succeeded in a single trial (Lubow, Schnur, \& Rifkin, 1976). In contrast, successful demonstrations of conditioning to white noise and tone CSs are common, even with only one conditioning trial and regardless of whether the CS occurs before, during, or after the US (Burkhardt, 1980; Burkhardt \& Ayres, 1978; Mahoney \& Ayres, 1976; Shurtleff \& Ayres, 1981). The present paper provides some clues as to why the light may be seldom used in the lick-suppression literature. All of the experiments reported here directly compared the effects of lights and tones, and all used a single conditioning trial. In the first experiment, evidence was found for one-trial backward

This work was supported by Grant BNS 85-00277 from the National Science Foundation to John J. B. Ayres. We wish to thank Michael S. Fanselow and Terry L. DeVietti for their critical reading of an earlier draft of the manuscript, and we are grateful to Melody Albert for her support throughout the project. Requests for reprints should be addressed to John J. B. Ayres, Department of Psychology, Middlesex House, University of Massachusetts, Amherst, MA 01003. excitatory conditioning to a tone CS but not to a light. In the second, it was found that unconditioned lick suppression habituates to a tone CS faster than to a light, possibly explaining the greater ease of demonstrating more suppression to a paired CS than to an explicitly unpaired CS when both are tones than when both are lights. The third demonstrated that the failure of the light CS to show evidence of conditioning in terms of the lick-suppression measure is not unique to one-trial backward conditioning procedures but can occur in one-trial forward procedures as well. In the fourth experiment, CS duration was manipulated in a forward procedure in an attempt to enhance conditioning to the light. It also included direct observations of the rat's behavior in an effort to determine what rats actually do during tones and lights. Perhaps differences in behaviors evoked by tones and lights might account for the differences in lick suppression that these CSs evoke.

The research did not begin with any of the above issues in mind. Rather, it began as an attempt to devise a within-subject control procedure for the study of one-trial excitatory backward conditioning. Excitatory backward conditioning is of major interest because its existence seems to argue strongly against the widely accepted view that a CS must signal or predict the onset of a US in order to gain excitatory conditioned strength. One-trial procedures in general are interesting because: (1) they eliminate complications possibly arising from the learning of "autocontingencies" (Davis, Memmott, \& Hurwitz, 1975), that is, learning that USs predict other USs, learning that there are $x$ USs per session, and so forth; (2) they permit the manipulation of factors such as CS duration or CS-US interval without confounding with trial spacing effects (Kaplan, 1984; Stein, Sidman, \& Brady, 1958; Yeo, 
1974); and (3) they simplify the selection of control procedures by eliminating from consideration the truly random control (Rescorla, 1967), whose effects are known to be highly variable (Benedict \& Ayres, 1972; Keller, Ayres, \& Mahoney, 1977; Kremer, 1974; Quinsey, 1971). In backward conditioning, the one-trial procedure is of added interest because it ensures that the CS on trial $n$ cannot possibly predict the US on trial $n+1$.

Previous work on one-trial backward excitatory conditioning (Burkhardt, 1980; Keith-Lucas \& Guttman, 1975; Mahoney \& Ayres, 1976; Shurtleff \& Ayres, 1981) has used between-subjects control procedures. In those studies, experimental subjects received a single backward pairing of a CS and a US, and control subjects received either the US alone or the CS and the US explicitly unpaired. Such a design seems unnecessarily wasteful of time and subjects, particularly so if parametric work is contemplated; here, one might envision a separate control group for each level of the manipulated parameter. It would seem much more efficient to present a backwardpaired CS, such as a tone, and an explicitly unpaired CS, such as a light, in the same session to the same subject and then look for a difference in the response to these two stimuli; naturally the two stimuli would be counterbalanced. Experiment 1 directly compared the betweensubjects design previously used with the within-subjects design just described.

\section{EXPERIMENT 1}

\section{Method}

Subjects. Forty experimentally naive male albino rats, 90 days old on arrival from the Holtzman Company, Madison, Wisconsin, served as subjects. Each rat was individually housed in a suspended wire-mesh cage in a continuously lighted room maintained at about $76^{\circ} \mathrm{F}$. The rats were watered and fed freely for a week before the study was started.

Apparatus. One Gerbrands operant conditioning box with its bar slot and recessed dipper tray covered with metal plates was housed in a ventilated $.61-\mathrm{m}$ cube of $12.7-\mathrm{mm}$ plywood lined with white acoustical tile. The inside dimensions of the box were $23.2 \times 20.3$ $\times 19.5 \mathrm{~cm}$. The floor was made of 18 stainless steel rods, $2 \mathrm{~mm}$ in diameter, mounted $1.3 \mathrm{~cm}$ apart center to center. The end walls were aluminum, and the sides and top were clear Plexiglas. In one side wall was a $5.1 \times 1.3 \mathrm{~cm}$ horizontal slot that gave access to a lick tube outside the box. The tube was insulated with heatshrinkable tubing except for its tip, and was attached to a bottle of tap water and to a Grason-Stadler drinkometer (Model E4690A-1) that recorded licks. The end wall to the rat's right as it faced the lick tube had a 28-V white cue light (used only in Experiment 3) mounted $10 \mathrm{~cm}$ above the floor and $3 \mathrm{~cm}$ from the wall with the tube. One CS was a $1000-\mathrm{Hz} 87-\mathrm{dB}$ tone provided by a HewlettPackard audio oscillator through a $10-\mathrm{cm}$-diam speaker mounted on the box lid. A second CS was provided by lighting a 7.5-W 110-V frosted white bulb mounted on the rear wall of the housing cube $20 \mathrm{~cm}$ above its floor. The bulb was $15 \mathrm{~cm}$ from the Plexiglas wall opposite the one with the lick tube, and it produced a reading of $16 \mathrm{~lx}$ on a Pasco Scientific photometer with its selenium cell aimed through the lick slot directly at the bulb. The US was a 4-sec 1-mA scrambled grid shock provided by a high-voltage, high-resistance shock source and scrambled through a relay sequencing scrambler
(Hoffman \& Fleshler, 1962). All events were controlled and recorded by a computer in a nearby room.

Procedure. One week after their arrival, the rats were deprived of water, and $24 \mathrm{~h}$ later they were put in the conditioning box with the lick tube inserted. The 100th lick initiated a $2-$ min dummy CS (no stimulus change from the rat's view), after which the session ended and the rats were watered for $.5 \mathrm{~h}$ in their home cages. Measures recorded in the conditioning box included the time between licks 90 and 100 (defined as the pre-CS time) and the time between licks 100 and 110 (defined as the CS time). Rats that failed to emit the 110th lick before the 2-min period ended were given a CS time of $120 \mathrm{sec}$. This procedure was repeated on Days 2, 3, and 4, except that the lick tube was pulled about $1 \mathrm{~cm}$ outside the slot so as to prevent all but tongue contacts.

On Day 5 the rats received a one-trial conditioning procedure. They were placed individually in the conditioning box with no lick tube available, and were given a single 4-sec 1-mA grid-shock US that began $214 \mathrm{sec}$ into a 432 -sec session. A between-groups design like that used in previous work was used for Groups $+T$ and T/+ (e.g., Shurtleff \& Ayres, 1981). For Group +T, the 4-sec tone CS began $4 \mathrm{sec}$ after US onset (backward conditioning procedure). For Group $T /+$, the 4-sec tone terminated $3 \mathrm{~min}$ before US onset (explicitly unpaired procedure). (For a comparison of explicitly unpaired controls and US-alone controls and for a discussion of the adequacy of the baselines they provide, see Mahoney \& Ayres, 1976, p. 360.) A within-subjects design was used for two other groups, Groups $L /+T$ and $T /+L$. For Group $L /+T$, the (explicitly unpaired) light CS terminated 3 min before US onset, and the (backward-paired) tone CS began $4 \mathrm{sec}$ after US onset. For Group $\mathrm{T} / \mathrm{L}$, the modality of the explicitly unpaired and backwardpaired CSs was reversed. Ten rats were assigned randomly to each of these four groups. After the session, the rats were given water in their home cages for $.5 \mathrm{~h}$ as usual.

On Days 6 and 7, the rats were treated just as during the last 3 days of lick training, except that the tone replaced the dummy CS on Day 6 and the light did so on Day 7. ${ }^{1}$ Pre-CS and CS times were recorded as before, and CS times were used as a measure of conditioned suppression to the CSs; longer times mean more suppression.

Treatment of data. Previous papers from this laboratory describing experiments similar to the present one (Burkhardt \& Ayres, 1978; Mahoney \& Ayres, 1976; Shurtleff \& Ayres, 1981) reported group median CS times and analyzed the results using nonparametric statistical procedures. Other laboratories, however, routinely convert the CS times to logs (base 10), report group means and standard errors of the mean of those logs, and use parametric analyses of variance (ANOVAs) on the log scores (e.g., Kasprow et al., 1982; Marlin, 1983). In an effort to conform with these laboratories and to benefit from the more powerful parametric analyses, we adopted all of these practices here. We shall, in addition, continue to describe group median CS times to ensure some comparability with our previous reports and because the untransformed CS times seem to give a better feel for the data than do the log transforms. Besides analyzing the $\log$ CS times, we also did identical analyses on both the raw and $\log$ pre-CS times. None of the latter analyses revealed any significant effects, however; so the differences that we describe in terms of $\log$ CS times are not complicated by unintended differences in these baseline measures.

\section{Results}

Figure 1 shows the results of Experiment 1 . A $2 \times 2$ ANOVA was performed on the $\log$ CS times to the tone CS. Factors were design (between vs. within) and sign of the CS (CS + [i.e., backward paired] vs. CS - [i.e., explicitly unpaired]). The main effect of sign was signifi- 


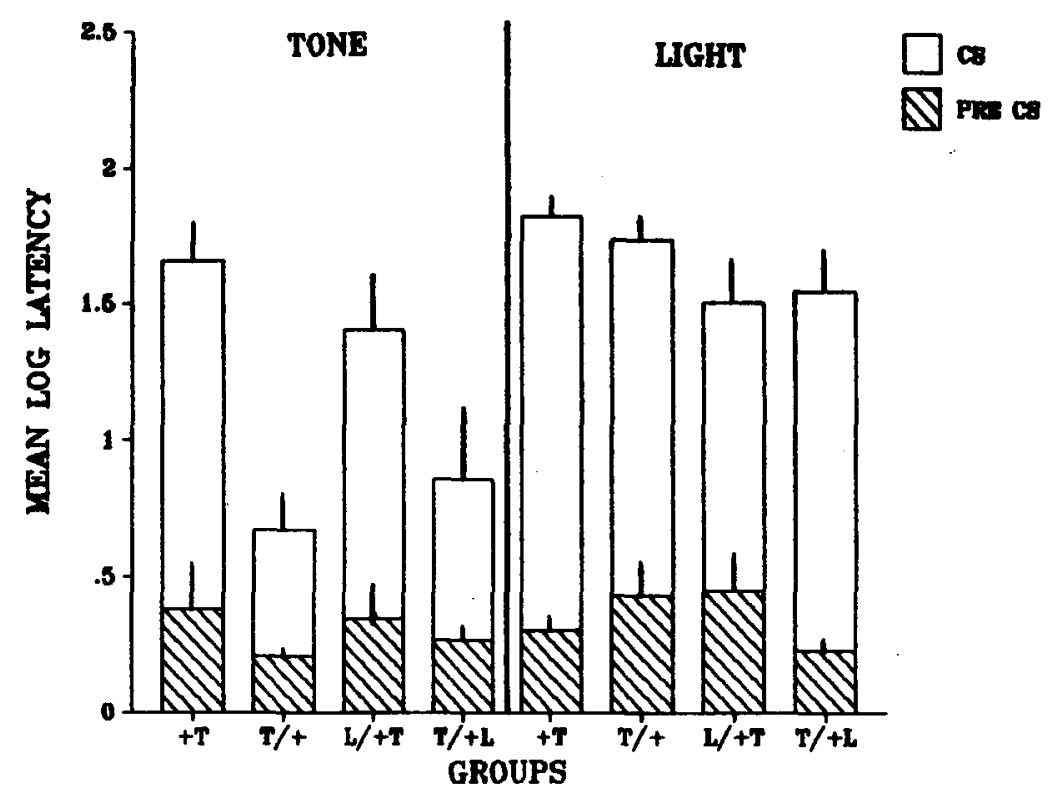

Figure 1. Mean log pre-CS times (striped part of bar) and CS times (entire bar) during CS testing in Experiment 1. Vertical lines above bars show one standard error of the mean. Group labels show the exact order of events for each group during conditioning. Thus, $+\mathbf{T}$ means that a shock was followed immediately by tone (backward conditioning); $L /+T$ means that an explicitly unpaired light was followed 3 min later by a backward-paired tone.

cant $[F(1,36)=16.74, p<.01]$, indicating more suppression to the backward-paired CS than to the explicitly unpaired CS. The main effect of design and the sign $\times$ design interaction did not approach significance $(F \mathrm{~s}<1.5)$, suggesting that the between- and withingroups designs produced comparable results. A similar $2 \times 2$ ANOVA was also performed on the log CS times to the light CS. No effects were significant; thus no evidence for excitatory backward conditioning to the light $\mathrm{CS}$ was obtained. Figure 1 suggests that there was more suppression to the explicitly unpaired light than there was to the explicitly unpaired tone. A $t$ test comparing the mean $\log$ CS time to the light in Group $\mathrm{L} /+\mathrm{T}$ with that to the tone in Group $\mathrm{T} / \mathrm{L}$ confirmed this impression $[t(18)=2.27, p<.05]$.

Group median CS times during the tone test were 46.7, $3.2,33.9$, and $3.8 \mathrm{sec}$ for Groups $+\mathrm{T}, \mathrm{T} /+, \mathrm{L} / \mathrm{T}$, and $\mathrm{T} /+\mathrm{L}$, respectively. Group median CS times to the light, in the same order, were $75.2,43.5,39.9$, and $48.3 \mathrm{sec}$. Group median pre-CS times during the tone test ranged from 1.61 to $1.70 \mathrm{sec}$; during the light test, they ranged from 1.61 to $1.72 \mathrm{sec}$.

\section{Discussion}

The results with the tone CS replicate previous findings that, after a single trial, lick suppression to a backward-paired CS is greater than that to an explicitly unpaired CS, results taken as evidence for one-trial excitatory backward conditioning (Burkhardt, 1980; Mahoney \& Ayres, 1976; Shurtleff \& Ayres, 1981); they also extend those results to a situation in which an explicitly unpaired light CS occurs in the same conditioning session as the backward-paired tone. However, no evidence for backward excitatory conditioning to the light was found. It is notable that all previous demonstrations of one-trial excitatory backward conditioning in the licksuppression procedure involved auditory CSs (tones or white noise).

As shown in Figure 1, the light produced strong suppression even in groups for which it had been explicitly unpaired with shock or not experienced at all. It is not clear whether this suppression reflects the unconditioned effects of the light (i.e., the light's ability to elicit an orienting response [OR], for example, approaching the light source) or whether it reflects sensitization of the CSOR reflex by the shock. It is clear, however, that the large nonassociative effects of the light, together with its failure to give any evidence of excitatory conditioning, contraindicate any within-subject comparisons between explicitly unpaired and backward-paired light and tone CSs.

The results of this experiment raise several questions about the light CS: (1) Is shock necessary for its strongly suppressive effects, or do those effects reflect only the normal unconditioned effects of the light? (2) What can be done to reduce those effects? (3) Is the failure of the light to condition unique to our one-trial backward conditioning procedure, or might it also occur in a similar one-trial forward procedure? Experiment 2 addressed the first two questions, and Experiments 3 and 4 addressed the third. 


\section{EXPERIMENT 2}

Experiment 2 compared the unconditioned effects of the light and tone in the absence of any shock US.

\section{Method}

Twenty experimentally naive male albino rats similar to those of Experiment 1 were housed and water deprived as before. The apparatus was unchanged except that the wooden front door of the cube that held the conditioning box was replaced by a portable door made from two sheets of clear Plexiglas screwed to opposite sides of a $6.5-\mathrm{cm}$ wooden frame. The room was illuminated with a $40-\mathrm{W}$ $115-\mathrm{V}$ red bulb in a gooseneck lamp placed about $1.5 \mathrm{~m}$ from the Plexiglas door. These two changes in apparatus were designed initially to permit casual observation of the rat at all times. (Later, in Experiment 4, observation was systematic.) The procedure was similar to the lick training procedure of Experiment 1, except that it lasted for 6 days and on each day the dummy CS was replaced by the light or tone. For all rats, the order of exposure was light, tone, tone, light, light, tone. The experiment was run in two replications with 11 rats in the first and 9 in the second.

\section{Results}

The results of the three trials for each stimulus are shown in Figure 2. The data for the two replications are combined, as there were no significant effects involving the replications factor. It is clear from the figure that on the first trial the two stimuli produced similar levels of suppression but that over the next two trials the unconditioned suppression habituated faster to the tone than to the light. These impressions were confirmed by a $2 \times$ $2 \times 3$ ANOVA in which the factors were replications, stimuli, and trials. Significant effects were trials $[F(2,36)$ $=19.39, p<.01]$, stimuli $[F(1,18)=4.55, p<.05]$, and the trials $\times$ stimuli interaction $[F(2,36)=3.39$, $p<.05]$. An identical ANOVA on the log pre-CS times

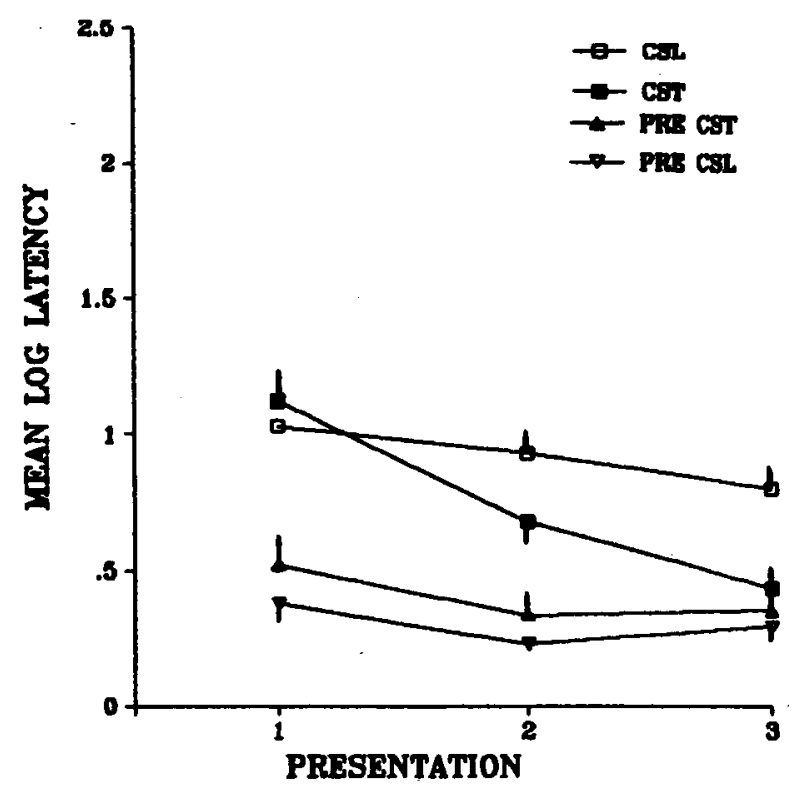

Figure 2. Mean log pre-CS times and CS times during habituation presentations in Experiment 2. Vertical lines above or below symbols show one standard error of the mean. showed the only significant effect was that of trials $[F(2,36)=3.38, p<.05]$, reflecting presumably the decrease in log pre-CS times across the first and second trials for both stimuli.

Median CS times across the three trials were 11.62, 4.14 , and $2.06 \mathrm{sec}$ for the tone and $16.33,9.05$, and $5.24 \mathrm{sec}$ for the light. Corresponding median pre-CS times were $2.24,1.66$, and $1.61 \mathrm{sec}$ for the tone and $1.93,1.55$, and $1.55 \mathrm{sec}$ for the light.

\section{Discussion}

In Experiment 1, after an explicitly unpaired presentation of tone and shock or light and shock, rats suppressed more to the light than to the tone. In the present study, however, in the absence of any shock, the unconditioned suppression to the two stimuli appeared similar on their first presentation; on later trials, that unconditioned suppression weakened more rapidly for tone than for light. This pattern of results suggests that the differences between the unpaired tone and light in Experiment 1 could have reflected greater habituation to the tone during the explicitly unpaired procedure. In addition, in Experiment 1 , there may have been some sensitization to the light; comparison of Figures 1 and 2 suggests that there was less suppression to the light in Experiment 2 than in Experiment 1. Such a difference could reflect sensitization in Experiment 1 and its absence in Experiment 2.

\section{EXPERIMENT 3}

Because Experiment 1 demonstrated apparent one-trial backward excitatory conditioning to a tone but not to a light, we wanted to see if the problem with the light was unique to the one-trial backward procedure. Evidence that it might be was suggested by a previous study of lick suppression that claimed to have demonstrated conditioning to a light after only one CS-US pairing (Lubow, Schnur, \& Rifkin, 1976, Experiment 1). In that study, each rat received a presentation of a 3-sec light CS that terminated in the onset of a 1-sec 1-mA shock; later the rats were tested for suppression to the light, and that suppression was found to be quite strong. However, there were no control groups in that study; therefore, it is impossible to know whether the strong suppression to the light reflected the normal unconditioned effects of the light, the sensitized effects of the light, or the conditioned effects of the light.

The present study compared conditioning to a light and a tone in a one-trial forward conditioning procedure. The method was similar to that of Experiment 1 except that a forward rather than a backward pairing was used. In addition, the light CS was modified on the basis of the following considerations. In Experiments 1 and 2, the light brightly illuminated the entire box and was clearly detected by the rats as evidenced by the extensive lick suppression that it produced. However, in the lick tests, the rat always had its back turned to the bulb when licking, whereas, during the conditioning trial, the rat's position 
in the box was highly variable. If the rats looked directly at the bulb during conditioning but not during testing, this might result in a generalization decrement that would prevent the full expression of the conditioned response. In an effort to reduce this possibility, we added a second bulb directly in front of the lick tube, $11 \mathrm{~cm}$ outside the conditioning box. In addition, a prior demonstration of conditioning to a light $\mathrm{CS}$ in a multitrial lick-suppression procedure (Kasprow et al., 1982) presented the light CS against a dimly lit background. In an effort to approximate this feature, we presented our light CS against a background provided by the continuous operation of the 28 -V cue light on the end wall to the rat's right as it faced the lick tube. This light produced a reading of $.5 \mathrm{~lx}$ on our photometer, which was positioned exactly as described in Experiment 1.

\section{Method}

The subjects were 27 experimentally naive rats similar to those used before and kept under identical conditions. The apparatus was that of Experiment 1 except for the addition of a second 7.5-W $110-\mathrm{V}$ frosted white bulb placed in front of the lick tube $11 \mathrm{~cm}$ outside the box. This bulb was used as a CS along with the original bulb of Experiments 1 and 2. The two bulbs together increased the background illumination provided by the continuous operation of the $28-\mathrm{V}$ cue light mounted on the end wall to the rat's right as it faced the lick tube. All procedures were those of Experiment 1 except that during conditioning, the paired CS began 4 sec before US onset. A between-groups design was used. For Group T+ $(n=7)$, the 4-sec tone terminated in the onset of the 4-sec shock; for Group $T /+(n=6)$, the tone terminated $180 \mathrm{sec}$ before shock onset. For Groups $\mathrm{L}+$ and $\mathrm{L} /+(n \mathrm{~s}=7)$, the light $\mathrm{CS}$ replaced the tone. On the day after conditioning, each rat was tested for suppression to its trained CS.

\section{Results}

The results of the test day are shown in Figure 3. The figure suggests stronger suppression to the paired tone than to the paired light but somewhat weaker suppression to the unpaired tone than to the unpaired light. Due to these tendencies, the difference between suppression to paired versus unpaired CSs appears larger for the tone groups than for the light groups. These impressions were confirmed by a $2 \times 2$ ANOVA on the $\log$ CS times; factors were stimuli (tone vs.light) and treatment (paired vs. unpaired). The analysis revealed the effects of treatment $[F(1,23)=13.39, p<.01]$ and the treatment $\times$ stimulus interaction $[F(1,23)=4.17, p<.05]$ to be significant. The difference between paired and unpaired CSs was analyzed further with $t$ tests, using the between-groups error term and degrees of freedom from the ANOVA. These tests found a significant difference between paired and unpaired tones $[t(23)=3.73, p<.01]$ but not between paired and unpaired lights $(t<1)$.

Median CS times for Groups $\mathrm{T}+, \mathrm{T} /+, \mathrm{L}+$, and $\mathrm{L} /+$, respectively, were $120.0,5.8,42.0$, and $24.4 \mathrm{sec}$. Median pre-CS times in the same order were $1.77,1.80$, 1.90 , and $1.57 \mathrm{sec}$.

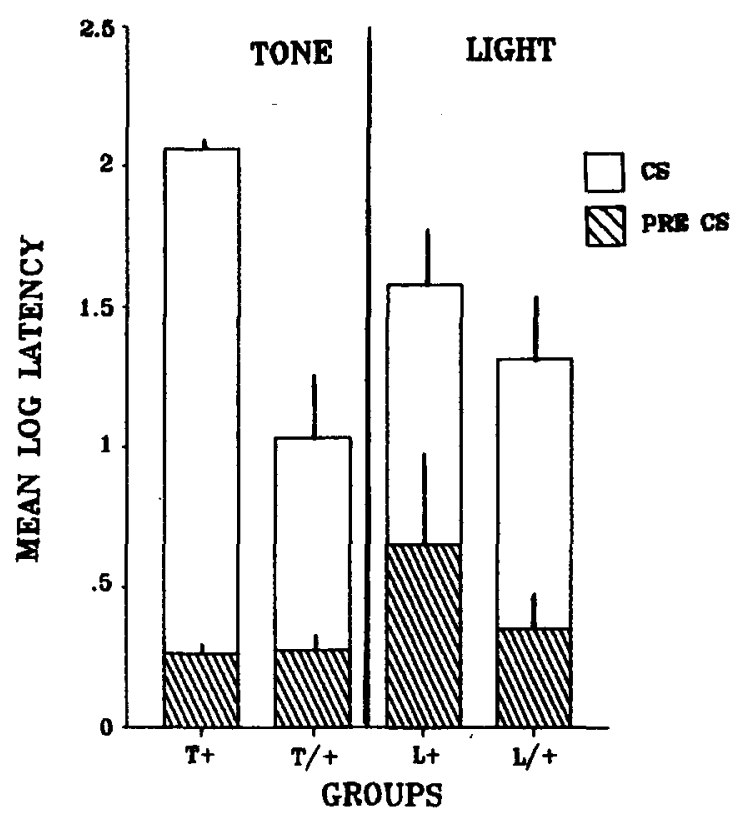

Figure 3. Mean log pre-CS times (striped part of bar) and CS times (entire bar) during CS testing in Experiment 3. Vertical lines above bars show one standard error of the mean. Group labels show the exact order of the events for each group during conditioning. Thus, $\mathbf{T}+$ means that a tone was followed immediately by shock (forward conditioning procedure); $\mathbf{L} /+$ means that an explicitly unpaired light was followed $3 \mathrm{~min}$ later by a shock.

\section{Discussion}

Experiment 3 demonstrated one-trial forward conditioning to a tone CS but failed to do so to a light CS. Part of the problem appeared to be the large unconditioned or sensitized suppression to the light in the explicitly unpaired control, but another problem was that suppression to the paired light was also weaker than suppression to the paired tone. Thus, the failure of the light to show conditioning does not seem to have been peculiar to the backward conditioning procedure of Experiment 1.

The introduction to this experiment mentioned a study that purported to have demonstrated one-trial forward conditioning to a light CS (Lubow et al., 1976, Experiment 1). That study used a suppression ratio to index the strength of conditioning. The ratio was defined as dummy CS time/(dummy CS time + CS time). The dummy CS time was taken from the last day of lick training, and the CS time was taken from the test day. Ratios near .50 denoted no effect of the CS, and those near 0 denoted strong suppression. For the forward-paired light group in that study, the group mean ratio on the test trial was .05 . This strong suppression was taken as evidence of conditioning to the light CS. As there were no conditioning control groups in that study, it is of some interest to ask what the ratio was in the present explicitly unpaired control. Accordingly, we calculated this ratio for our explicitly unpaired light control and found the median for 
the group to be .04 . Naturally, the similarity of our ratio to the previous one does not prove that one-trial conditioning to the light did not occur in the previous work, but it certainly reinforces the possibility that the suppression obtained in that study could have reflected either the normal unconditioned suppression or sensitized suppression to the light CS.

\section{EXPERIMENT 4}

Experiment 4 had two aims. The first was to compare again one-trial forward conditioning to a light and tone $\mathrm{CS}$ in the lick-suppression procedure, but now at two different CS durations: 4 and $12 \mathrm{sec}$. This comparison was suggested by the work of Yeo (1974), who, using a onetrial forward conditioning procedure in which the CS and a 1-sec US terminated together, showed that test suppression increased with conditioning CS durations from 1.3 to $11 \mathrm{sec}$ and declined from 11 to $91 \mathrm{sec}$. From his work, it appeared that a 12-sec CS duration would be close to optimal; it should increase suppression to the paired CS and possibly produce more habituation of unconditioned suppression to the explicitly unpaired CS. These effects should result in a larger difference between paired and unpaired light CSs than was seen in Experiment 3. The second aim of Experiment 4 was to see what the rats were actually doing during the tone and light CSs. Sigmundi and Bolles (1983), using a time-sampling technique, directly observed the freezing behavior of rats in the presence and absence of CSs that had been repeatedly paired with shock. They found that rats froze much more to a white-noise CS than to a light. On the basis of other evidence in their study, Sigmundi and Bolles suggested that their noise and light were equally well conditioned and that the differences in the levels of freezing to the two stimuli were due to the fact that they elicited different defensive behaviors. Later observations made by Ayres, Axelrod, Mercker, Muchnik, and Vigorito (1985) in a barpress conditioned suppression study were consistent with this idea. Ayres et al. found that intermittent white-noise and flashing-light CSs produced similar levels of barpress suppression, suggesting equal conditioning, but that noise evoked more freezing than did light. Since the light produced as much barpress suppression as the noise but did not produce as much freezing, the light must have produced other (presumably defensive) behaviors that competed with barpressing. Perhaps these different behaviors could account for the differences in the abilities of auditory and light CSs to control lick suppression in the preceding studies. Experiment 4 therefore sought to determine what the rat was actually doing during the tone and light CSs in the lick-suppression test.

\section{Method}

The subjects were 32 experimentally naive rats similar to those of the prior experiments and maintained as before. The apparatus was that of Experiment 2 . The light CS consisted once again of the illumination of the two 7.5-W 110-V bulbs, as in Experiment 3, but now presented in a totally dark box; thus, the $28-\mathrm{V}$ cue light of Experiment 3 was not used. The procedure was similar to that of Experiment 3 except that two CSs were given during conditioning. One, the forward-paired CS (CS+) terminated in the onset of the shock US; the other, the explicitly unpaired CS (CS-) terminated $180 \mathrm{sec}$ before the US began. As before, the US was the 4$\sec 1-\mathrm{mA}$ shock, and it began $214 \mathrm{sec}$ into the $432-\mathrm{sec}$ session. For Group $12 \mathrm{~L} / \mathrm{T}+$, the CSs were each $12 \mathrm{sec}$ in duration; tone was $\mathrm{CS}+$ and light was CS - . For Group $12 \mathrm{~T} / \mathrm{L}+$, the CSs were also $12 \mathrm{sec}$, but the tone was CS - and the light was CS + . Two other groups, $4 \mathrm{~L} / \mathrm{T}+$ and $4 \mathrm{~T} / \mathrm{L}+$, received treatments that should be clear from their labels. Eight rats were assigned to each group in such a way as to match the groups in terms of their dummy CS times on the 4th day of lick training. Testing for suppression to each stimulus required 2 days. Half the rats in each group were tested with tone on the 1st day and light on the 2 nd. For the other half, the order was reversed.

During the conditioning day and during the test of each stimulus, the rats' behavior was directly observed using a time sampling technique. Paced by a $1 / \mathrm{sec}$ click of a relay, which was present during every session, the experimenter looked at the rat in every second of a CS and described the rat's behavior into a tape recorder. Only one of four behavioral categories was described in each second: $F, N, R$, or $\mathbf{O}$. F, freezing behavior, was defined as absence of any movement except those movements of the rat's sides required for breathing. N, nosing behavior, was defined as placement of the rat's nose on the lick slot, regardless of whether the rat was actually licking. (However, if the rat froze with its nose on the slot, that behavior was scored as freezing.) $\mathbf{R}$, rearing behavior, was defined as the removal of both forepaws from the floor. $O$, other behavior, was defined as anything other than $F, N$, or $R$. The experimenter was warned of CS occurrence by a small blue light located outside the rats' line of sight. This light occurred $5 \mathrm{sec}$ prior to CS onset during conditioning and was turned on by the 90th lick during testing. The experimenter was not naive about the rats' group assignments but was naive about potential outcomes. Probably because of the random order in which subjects were run, the experimenter was unable to describe any pattern in the rats' behavior until after all the results were tabulated.

\section{Results}

Lick suppression. Figure 4 shows the lick suppression test results of Experiment 4. The figure shows clear evidence for conditioning to the tone; that is, suppression to the tone CS + appears much greater than suppression to the tone CS - . There also appears to be more suppression to the light CS + than to the light CS-, but this effect is not as pronounced as it is with the tone and it is the smallest of all in the 4-sec CS duration condition.

The $\log$ CS times were subjected to a $2 \times 2 \times 2$ mixeddesign ANOVA. Between-subjects factors were modality of CS+ (tone vs. light) and CS duration (4 vs. $12 \mathrm{sec}$ ). The within-subjects factor was the sign of the CS (CS + or CS -). The analysis found a significant effect of sign of the $\operatorname{CS}[F(1,28)=292.90, p<.0001]$, reflecting the stronger suppression to CS + than to CS - . It also found a significant effect of modality of $C S+[F(1,28)=30.4$ $p<.0001$ ], indicating that suppression (averaged over $\mathrm{CS}+$ and $\mathrm{CS}-$ ) was greater in groups for which tone was $\mathrm{CS}+$ than in groups for which light was CS + . Note that this effect reflects not only the tendency toward more suppression to the paired tone but also more suppression to the unpaired light, since if a group received tone as its 
TONE UIGHT

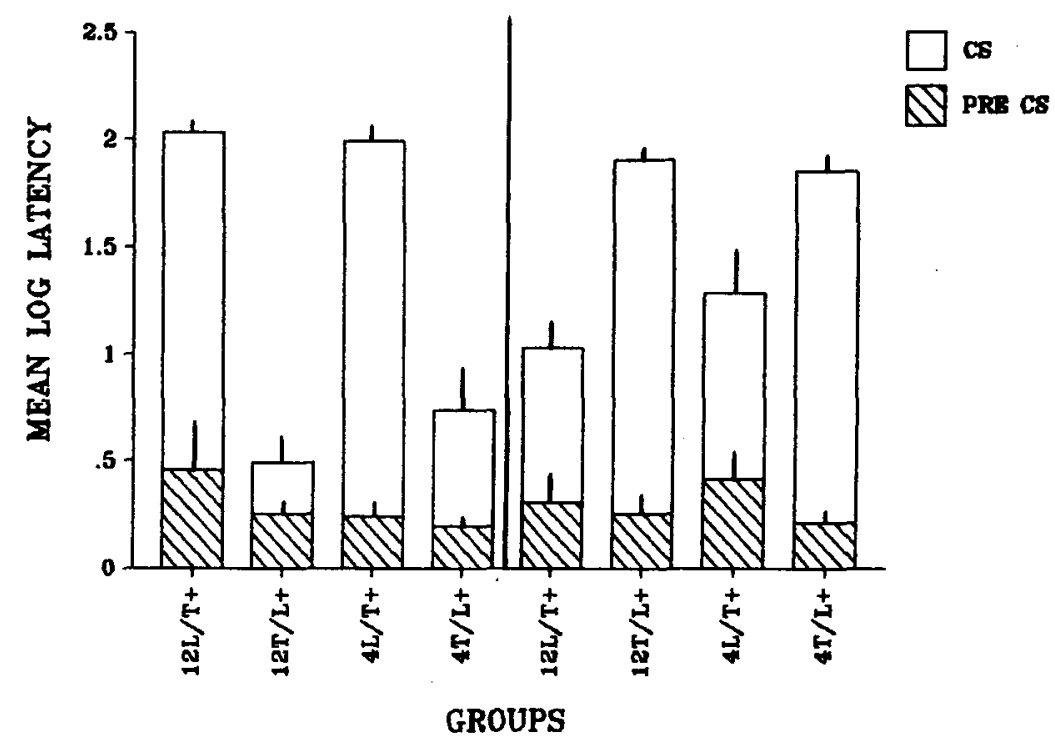

Figure 4. Mean log pre-CS times (striped part of bar) and CS times (entire bar) during CS testing in Experiment 4. Vertical lines above bars show one standard error of the mean. Group labels show the exact order of the events for each group during conditioning. Thus, 12L/T + means that a 12-sec explicitly unpaired light was followed 3 min later by a 12-sec forward-paired tone; $4 T / L$ + means that a 4-sec explicitly unpaired tone was followed $3 \mathrm{~min}$ later by a 4 -sec forward-paired light.

$\mathrm{CS}+$, it also received light as its $\mathrm{CS}-$. The sign $\times$ modality interaction was also significant $[F(1,28)=10.5$, $p<.005]$. Simple effects tests indicated that this effect was due to a significantly greater suppression to the light CS - than to the tone CS $-[t(28)=4.91, p<.0001]$ and a nonsignificant tendency for more suppression to the tone $\mathrm{CS}+$ than to the light CS + . Finally, the sign $\times$ duration effect was also significant $[F(1,28)=5.60, p<.03]$. Simple effects tests revealed that this effect was due to a significant decrease in suppression to CS - with increasing CS duration in conditioning $[t(28)=2.27, p<.05]$ combined with a nonsignificant increase in suppression to $\mathrm{CS}+$ with increasing CS duration in conditioning.

Because the difference between the 4-sec paired and unpaired light was not significant in Experiment 3, it is of interest to ask whether that difference was significant for the groups that received the 4-sec CS durations during conditioning in Experiment 4. In Experiment 4, the difference was significant $[t(28)=5.06, p<.01]$. A comparison of Figures 3 and 4 suggests that the suppression to the explicitly unpaired light was similar in the two experiments but that there was more suppression to the paired light in Experiment 4; there was also less variability in the data of Experiment 4. Whether these differences between experiments are due to differences in the light CSs used or to other factors, including differences between shipments of rats, is unclear.

Group median CS times to the tone were 120.00 , $120.00,2.15$, and $4.68 \mathrm{sec}$ for Groups $12 \mathrm{~L} / \mathrm{T}+, 4 \mathrm{~L} / \mathrm{T}+$, $12 \mathrm{~T} / \mathrm{L}+$, and $4 \mathrm{~T} / \mathrm{L}+$, respectively. Group median CS times to the light in the same order were $9.62,18.11$,
79.31 , and $69.75 \mathrm{sec}$. Group median pre-CS times ranged from 1.49 to $1.76 \mathrm{sec}$ during the tone tests and from 1.51 to $2.28 \mathrm{sec}$ during the light tests.

Observational measures. Figure 5 shows the behaviors that were directly observed in Experiment 4 . The top two panels show the results obtained on the conditioning day. Here the labels " $S+$ " and " $S-$ " indicate whether the stimulus would be defined as a $\mathrm{CS}+$ or $\mathrm{CS}-$ once the US occurred. Because these data were collected prior to US onset, they reflect only the unconditioned effects of the CSs; and they are not expected to change with the sign of the CS. If they did, that might suggest a possible sampling error or might raise questions about the reliability of the experimenter's observational techniques. The results of the 12-sec CS conditions are based on $12 \mathrm{ob}-$ servations per rat; those for the 4-sec conditions are based on only 4 observations per rat. For each rat, a percent score (e.g., a percent freezing score) was obtained by dividing the number of times that behavior was observed by the total number of observations ( 4 or 12). The arithmetic mean of these percent scores for each group under each CS condition is plotted in the figure.

The top two panels show that freezing and nosing were rare during conditioning. Freezing was especially rare during the light ( $M=1 \%$ for light vs. $7 \%$ for tone); indeed, it was not reported at all for three of the four groups. By far the most likely behaviors during conditioning with both light and tone CSs were rearing and "other."

The bottom two panels show the results of main interest, that is, the results of testing the two stimuli after conditioning. Here the labels " $S+$ " and " $S-$ " denote whether 

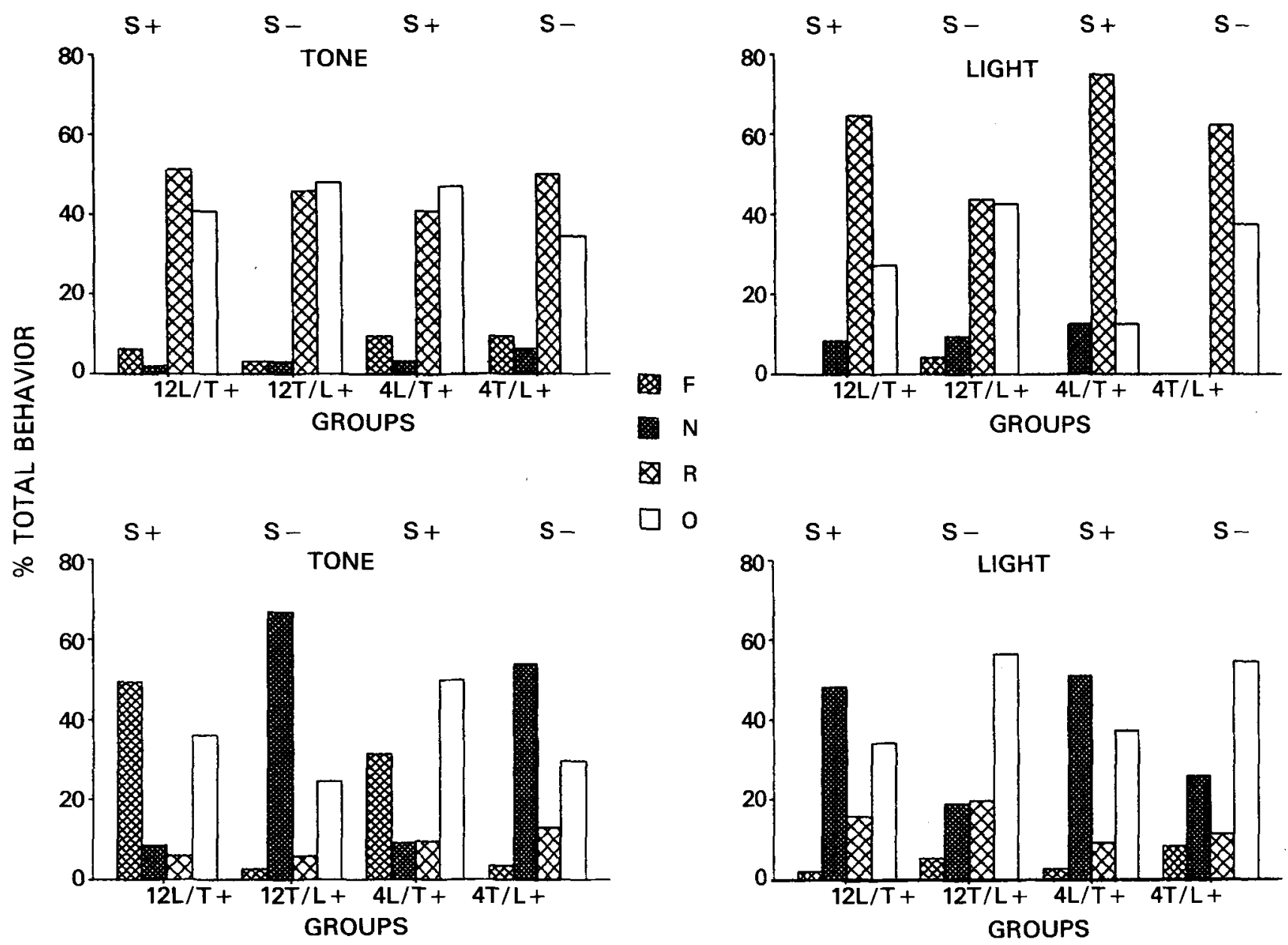

Figure 5. Mean percent of observation samples scored as freezing (F), nosing $(\mathbb{N})$, rearing (R), and “other” (O) in Experiment 4. Top panels show conditioning data; bottom panels show test data. Group labels show the exact order of the events for each group during conditioning. Thus, 12L/T + means that a 12-sec explicitly unpaired light was followed 3 min later by a 12-sec forward-paired tone; 4T/L + means that a 4-sec explicitly unpaired tone was followed 3 min later by a 4 -sec forward-paired light.

the CS served as $\mathrm{CS}+$ or $\mathrm{CS}-$ on the conditioning day. In these two panels, the results are expected to change with the sign of the CS. For each rat, the percent measures were based on 120 observations with two exceptions: Due to a recording problem, the percent measures were based on only 53 observations during CS - for 1 rat in Group $4 \mathrm{~L} / \mathrm{T}+$ and on only 27 observations during CS - for 1 rat in Group $12 \mathrm{~T} / \mathrm{L}+$.

Inspection of the bottom two panels suggests the following conclusions: Relative to $\mathbf{C S}-, \mathrm{CS}+$ produced a suppression of nosing. This was true for both tones and lights and for both CS duration conditions. Also, for both tones and lights, the suppression in nosing was accompanied by increases in freezing and "other" behaviors but by little change in rearing. For the tone CS, the suppression in nosing was accompanied by large increases in freezing relative to the increases in "other," whereas for the light CS, the reverse was true. There was little freezing in general to the light.
These summary statements are supported with more precision in Table 1. Its left side shows that relative to a CS - in the same modality, CS + suppressed nosing. For example, rats from the 12-sec CS condition nosed on $67 \%$ of the observations during the tone $\mathrm{CS}-$ and on only $9 \%$ during the tone CS + , a drop of $58 \%$. The middle and right parts of the table show how increases in freezing and "other" behaviors accounted for the drop in nosing. The column labeled "SUM" shows the sum of the increases in freezing and "other" behaviors. For the 12-sec tone condition, the sum of the increases in freezing and "other" behaviors completely accounted for the drop in nosing. The table makes the points that (1) in every condition, the sum of the increases in freezing and "other" behaviors closely approximated in size the drop in nosing, and (2) for tone CSs, the drop in nosing was accompanied by relatively large increases in freezing and relatively small increases in "other," but for light CSs, the reverse was true. 
Table 1

Mean Percent Nosing, Freeaing, and "Other" Behaviors During Testing

\begin{tabular}{|c|c|c|c|c|c|c|c|c|c|c|}
\hline \multirow{2}{*}{$\begin{array}{l}\text { CS Duration } \\
\text { (in Seconds) }\end{array}$} & \multicolumn{3}{|c|}{ Nosing } & \multicolumn{3}{|c|}{ Freezing } & \multicolumn{3}{|c|}{ "Other" } & \multirow[b]{2}{*}{ SUM } \\
\hline & $\mathrm{CS}-$ & $\mathrm{CS}+$ & drop & $\mathrm{CS}-$ & CS + & rise & $\mathrm{CS}-$ & $\mathrm{CS}+$ & rise & \\
\hline \multicolumn{11}{|c|}{ Tone } \\
\hline $\begin{array}{r}12 \\
4\end{array}$ & $\begin{array}{l}67 \\
54\end{array}$ & $\begin{array}{l}9 \\
9\end{array}$ & $\begin{array}{l}58 \\
45\end{array}$ & $\begin{array}{l}3 \\
4\end{array}$ & $\begin{array}{l}49 \\
31\end{array}$ & $\begin{array}{l}46 \\
27\end{array}$ & $\begin{array}{l}25 \\
30\end{array}$ & $\begin{array}{l}36 \\
50\end{array}$ & $\begin{array}{l}11 \\
20\end{array}$ & $\begin{array}{l}57 \\
47\end{array}$ \\
\hline \multicolumn{11}{|c|}{ Light } \\
\hline $\begin{array}{r}12 \\
4\end{array}$ & $\begin{array}{l}48 \\
51\end{array}$ & $\begin{array}{l}19 \\
26\end{array}$ & $\begin{array}{l}29 \\
25\end{array}$ & $\begin{array}{l}2 \\
3\end{array}$ & $\begin{array}{l}5 \\
8\end{array}$ & $\begin{array}{l}3 \\
5\end{array}$ & $\begin{array}{l}34 \\
37\end{array}$ & $\begin{array}{l}56 \\
55\end{array}$ & $\begin{array}{l}22 \\
18\end{array}$ & $\begin{array}{l}25 \\
23\end{array}$ \\
\hline
\end{tabular}

Note--In each row, the modality of the CS is held constant. For example, the first row compares behaviors evoked by tone CS - and tone CS +. The column labeled "SUM" shows the sum of the increases in freezing and "other" behaviors evoked by the CS + relative to the CS-.

Because the lick suppression measure failed to reveal the effect of CS duration that was expected from the work of Yeo (1974), it is interesting to ask whether any of the observational measures did so. Observational measures might be less constrained by ceiling effects than was the measure of lick suppression to the tone CS. The middle part of Table 1 shows freezing scores of $31 \%$ and $49 \%$ to the 4- and 12-sec tone CS +s, respectively. The direction of this effect is predictable from Yeo (1974), and the difference is significant $[t(28)=2.31, p<.05]$. No measure revealed a significant duration effect for the light, and no measure other than freezing revealed a significant duration effect for the tone.

\section{Discussion}

In Experiment 4, stimuli forward-paired with shock produced significantly more lick suppression than did stimuli that were explicitly unpaired. This was true both for light and tone CSs and for both 4- and 12-sec CS durations. As in the previous studies in this series, however, the difference between paired and unpaired CSs was greater when those CSs were tones than when they were lights. Paired tones tended to produce somewhat more suppression than did paired lights, and unpaired tones produced significantly less suppression than did unpaired lights. Increasing the conditioning CS duration from 4 to $12 \mathrm{sec}$ tended to increase test suppression to paired CSs while decreasing suppression significantly to unpaired CSs. This decrease in suppression to the unpaired CS as a function of the CS duration during the explicitly unpaired procedure appears to reflect increasing habituation of the unconditioned response to the CS. The failure of the longer CS duration to significantly increase suppression to the paired CS is probably a result of our arbitrary use of a 120-sec ceiling on the CS times. This is especially likely for the tone CS, with which, even in the 4-sec duration condition, 6 of 8 rats had CS times of $120 \mathrm{sec}$. It is less likely for the light CS because in that 4-sec duration condition only 2 of the 8 rats had CS times of $120 \mathrm{sec}$; the remaining 6 had scores below $90 \mathrm{sec}$. Our results with the light CS, then, may be viewed as a failure to replicate the findings of Yeo (1974), who, using a tone CS, found significantly more suppression to an 11-sec CS than to a $4-\sec \mathrm{CS} .^{2}$
The directly observed behaviors during testing revealed that the rats were doing different things during tones and lights. Both stimuli, if previously paired with shock, suppressed nosing, but only the tone produced much freezing. For the tone $\mathrm{CS}+$, the suppression of nosing was well accounted for by large increases in freezing and smaller increases in "other" behavior; for the light CS+, the suppression of nosing was well accounted for in terms of large increases in "other" behavior and small increases in freezing. This pattern of results is entirely consistent with Sigmundi and Bolles's (1983) suggestion that rats engage in different defensive behaviors to stimuli in different modalities. Freezing appears to be the dominant defensive behavior evoked by auditory $\mathrm{CS}+\mathrm{s}$, and "other" appears to be the dominant defensive behavior evoked by visual $\mathrm{CS}+\mathrm{s}$. This conclusion seems to have some generality in that it has held across a variety of situations. Sigmundi and Bolles (1983) observed it with white-noise and light CSs in a rather barren chamber in which the rat was neither licking nor barpressing for food. Ayres et al. (1985) observed it with intermittent white-noise and flashing-light CSs in a Skinner box, both when rats were and were not permitted to barpress for food. We observed it here with pure-tone and light CSs when rats were licking a water tube for water. ${ }^{3}$

Unfortunately, from Sigmundi and Bolles (1983), Ayres et al. (1985), and the present experiment, we do not gain a clear picture of what the "other" defensive behaviors are. We can only say that, in contrast to the suggestion of Ayres et al. (1985), they do not seem to include rearing. In the absence of a precise description of the "other" behaviors, it is impossible to know whether the defensive behaviors elicited by auditory and visual CSs differ qualitatively (implying that auditory and visual CSs gain equal associative strength) or only quantitatively (implying that auditory CSs gain more strength). For example, the criterion of freezing used in the three studies cited above was a stringent one-absence of all movement except for the movement of the rats' sides as required for breathing. If a rat were crouched in a frozen posture but moving its head in a slow swaying motion, that behavior would be scored as "other." That behavior is indeed commonly observed, and may represent only a less extreme form of freezing. If auditory CSs evoke more freezing 
and less of this "frozen sway" behavior, and if lights evoke less freezing and more "frozen sway" behavior, then the effects of visual and auditory CSs may differ only in degree and not in kind. The existing data do not permit a choice between these alternatives.

Regardless of what accounts for the ratio of freezing to "other' behaviors evoked by light and tone CSs, it seems plausible that differences in these ratios could be partly responsible for the differences in the abilities of these stimuli to reflect conditioning as measured in terms of lick suppression. For example, if freezing were less compatible with licking than "other" behaviors were, then there would be a tendency for less lick suppression to a light CS + than to a tone CS + . But conditioning cannot be measured solely in terms of the response to a CS+; in the present paradigm it must be assessed in terms of a difference in suppression to a CS + and a CS - . The lick-suppression measure reveals not only a tendency for more suppression to a tone $\mathrm{CS}+$ than to a light $\mathrm{CS}+$, but also a tendency for more suppression to a light CSthan to a tone CS - . Together, these two tendencies lead to judgments of weaker conditioning to light CSs. It is clear from Experiment 2 that the unconditioned effects of the explicitly unpaired tone habituate more rapidly than those of the explicitly unpaired light; and it is clear from Experiment 4 that a relatively small increase in the duration of the explicitly unpaired CS (from 4 to $12 \mathrm{sec}$ ) during conditioning significantly reduces the suppressive effects of that CS during testing. Thus, the greater suppressive effects of the light CS - appear to be due to the weaker habituation of an OR to light during the explicitly unpaired procedure. Unfortunately, however, our direct observations did not pinpoint the exact nature of that $O R$ (see Figure 5, bottom panels, $S-$ data).

\section{GENERAL DISCUSSION}

The present study has documented the existence of a modality effect in the lick-suppression procedure. In backward conditioning, a backward-paired CS produced more suppression than did an explicitly unpaired CS only when the CSs were tones. The light CS produced strong suppression whether it was backward-paired or explicitly unpaired. In forward conditioning, the modality effect was reflected in a smaller difference between a forward-paired CS (CS +) and an explicitly unpaired CS (CS-) when those CSs were lights than when they were tones. The size of this difference, in turn, reflected a tendency for stronger suppression to a paired tone than to a paired light, combined with weaker suppression to an unpaired tone than to an unpaired light. Increasing the duration of the CS during forward conditioning from 4 to $12 \mathrm{sec}$ reduced suppression to the unpaired CS without reducing suppression to the paired CS, and thus enhanced the conditioning measure for both tone and light. In this study, the effect of CS duration on suppression to a paired CS was not as clear as the effect on suppression to the unpaired CS. On the basis of the work of Yeo (1974), the increase in duration of the CS during conditioning was expected to increase lick suppression to the paired CS, but this did not happen. For the tone, a ceiling effect may have been responsible for the failure of this result to materialize. This possibility was supported by the fact that a measure of suppression presumably less subject to a ceiling effect, namely freezing, did reveal the expected effect of CS duration. For the light, the effect of CS duration on suppression did not materialize with either the licksuppression measure or the freezing measure, and it did not appear that a ceiling effect was to blame. This, then, was a second type of modality effect observed in the study. A third type of modality effect emerged when habituation of unconditioned suppression was shown to occur more rapidly to a tone than to a light, even though the initial effects of the two CSs were equal.

Direct observation of the rats' behavior during tone testing revealed that suppression of nosing (and therefore of licking) was accompanied by large increases in freezing and small increases in "other" behavior; during light testing, it was accompanied by large increases in "other" behavior and very small increases in freezing. This observation of more freezing to tone than to light is consistent with other recent reports (Ayres et al., 1985; Sigmundi \& Bolles, 1983), and it does not appear to be dependent upon some peculiarity of our tone and light CS. Modality differences in the ratio of freezing to "other" defensive behaviors could be partly responsible for the differences in judgments of conditioning to tone and light CSs, judgments based on the difference in lick suppression evoked by $\mathrm{CS}+$ versus CS - .

The present series of studies began as an attempt to develop a within-subject control procedure that would aid the investigation of excitatory backward conditioning. That attempt was thwarted by the occurrence of modality effects that precluded the use of the control procedure we had hoped to use. We then decided to investigate the modality effects in detail, including direct observations of what rats actually do during CSs of different modalities. Our findings now lead us back to our original topic-the topic of excitatory backward conditioning. Much of the evidence for that phenomenon comes from studies of lick suppression or barpress suppression. In those studies, suppression to a paired CS is usually compared with suppression to an explicitly unpaired CS or to a novel CS. Our present results show that unconditioned suppression to an explicitly unpaired CS habituates rapidly. But suppose a US in proximity to a CS, even a backward-paired CS, retards that habituation (cf. Lubow et al., 1976), or suppose that it even enhances the CS-OR reflex (Holland, $1977,1979 a, 1979 b, 1980 a, 1980 b$ ). If a backward-paired CS were to control a stronger OR than an explicitly unpaired or novel CS, then the backward CS would produce more lick or barpress suppression. With the exception of a procedurally complicated study by Keith-Lucas and Guttman (1975), none of the studies purporting to have demonstrated backward excitatory fear conditioning in rats reported any direct observation of the rats' behavior dur- 
ing testing. If the suppression evoked by the backward CS was accompanied by behaviors such as sniffing the speakers, approaching the light, rearing, or walking around, then we would have to question whether the CS was truly excitatory. If, however, the backward CS evoked freezing or even freeze-sway behavior, then the evidence for backward excitatory conditioning would be considerably strengthened.

\section{REFERENCES}

Ayres, J. J. B., Axelrod, H., Mercker, E., Muchnik, F., \& VIGorito, M. (1985). Concurrent observations of barpress suppression and freezing: Effects of CS modality and on-line vs. off-line training upon posttrial behavior. Animal Learning \& Behavior, 13, 44-50.

Benedict, J. O., \& Ayres, J. J. B. (1972). Factors affecting conditioning in the truly random control procedure in the rat. Journal of Comparative \& Physiological Psychology, 78, 323-330.

BURKHARDT, P. E. (1980). One-trial backward fear conditioning in rats as a function of US intensity. Bulletin of the Psychonomic Society, $15,9-11$

BurkhardT, P. E., \& AYres, J. J. B. (1978). CS and US duration effects in one-trial simultaneous fear conditioning as assessed by conditioned suppression of licking in rats. Animal Learning \& Behavior, 6, 225-230.

Davis, H., Memmott, J., \& Hurwitz, H. M. B. (1975). Autocontingencies: A model for subtle behavioral control. Joumal of Experimental Psychology: General, 104, 169-188.

HoffmAN, H. S., \& Fleshler, M. (1962). A relay sequencing device for scrambling grid shock. Journal of the Experimental Analysis of Behavior, 5, 329-330.

Holland, P. C. (1977). Conditioned stimulus as a determinant of the form of the Pavlovian conditioned response. Joumal of Experimental Psychology: Animal Behavior Processes, 3, 77-104

Holland, P. C. (1979a). Differential effects of omission contingencies on various components of Pavlovian appetitive conditioned responding in rats. Journal of Experimental Psychology: Animal Behavior Processes, 5, 178-193.

Holland, P. C. (1979b). The effects of qualitative and quantitative variation in the US on individual components of Pavlovian appetitive conditioned behavior in rats. Animal Learning \& Behavior, 7, 424-432.

Holland, P. C. (1980a). CS-US interval as a determinant of the form of Pavlovian appetitive conditioned responses. Journal of Experimental Psychology: Animal Behavior Processes, 6, 155-174.

Holland, P. C. (1980b). Influence of visual conditioned stimulus characteristics on the form of Pavlovian appetitive conditioned responding in rats. Journal of Experimental Psychology: Animal Behavior Processes, 6, 81-97.

KAPLAN, P. S. (1984). Importance of relative temporal parameters in trace autoshaping: From excitation to inhibition. Joumal of Experimental Psychology: Animal Behavior Processes, 10, 113-126.

Kasprow, W. J., Cacheiro, H., Balaz, M. A., \& Miller, R. R. (1982). Reminder-induced recovery of associations to an overshadowed stimulus. Learning \& Motivation, 13, 155-166.

KeITH-LuCas, T., \& GutTMaN, N. (1975). Robust-single-trial delayed backward conditioning. Journal of Comparative \& Physiological Psychology, 88, 468-476.

Keller, R. J., Ayres, J. J. B., \& MAHoney, W. J. (1977). Brief versus extended exposure to truly random control procedures. Journal of Experimental Psychology: Animal Behavior Processes, 3, 53-65.

KREMER, E. F. (1974). The truly random control procedure: Conditioning to the static cues. Journal of Comparative \& Physiological Psychology, 86, 700-707.

Leaf, R. C., \& Leaf, S. R. P. (1966). Recovery time as a measure of degree of conditioned suppression. Psychological Reports, 18, 265-266.

Leaf, R. C., Muller, S. A. (1965). Simple method for CER conditioning and measurement. Psychological Reports, 17, 211-215.

Lubow, R. E., SchNuR, P., \& RIFKIN, B. (1976). Latent inhibition and conditioned attention theory. Journal of Experimental Psychology: Animal Behavior Processes, 2, 163-174

MAHONEY, W. J., \& AYRES, J. J. B. (1976). One-trial simultaneous and backward fear conditioning as reflected in conditioned suppression of licking in rats. Animal Leaming \& Behavior, 4, 357-362.

MarLin, N. A. (1983). Second-order conditioning using a contextual stimulus as S1. Animal Learning \& Behavior, 11, 290-294.

QuINSEY, V. L. (1971). Conditioned suppression with no CS-US contingency in the rat. Canadian Journal of Psychology, 25, 69-82.

Rescorla, R. A. (1967). Pavlovian conditioning and its proper control procedures. Psychological Review, 74, 71-80.

SHURTLEF, D., \& AYRES, J. J. B. (1981). One-trial backward excitatory fear conditioning in rats: Acquisition, retention, extinction, and spontaneous recovery. Animal Learning \& Behavior, 9, 65-74.

Sigmund, R. A., Bolles, R. C. (1983). CS modality, context conditioning, and conditioned freezing. Animal Learning \& Behavior, 11, 205-212.

Stein, L., Sidman, M., \& Brady, J. V. (1958). Some effects of two temporal variables on conditioned suppression. Journal of the Experimental Analysis of Behavior, 1, 153-162.

VOGEL, J. R., SPEAR, N. E. (1966). Interaction of reward magnitude and conditioned fear on the consummatory response. Psychonomic Science, 5, 263-264.

YEO, A. G. (1974). The acquisition of conditioned suppression as a function of interstimulus interval duration. Quarterly Journal of Experimental Psychology, 26, 405-416.

\section{NOTES}

1. We intentionally avoided counterbalancing the order of the tone and light testing. Previous work in this laboratory (Mahoney \& Ayres, 1976; Shurtleff \& Ayres, 1981) had succeeded in demonstrating backward conditioning to auditory CSs but had never attempted to do so with light. In those studies, the auditory CS was tested on the day following conditioning. We wanted to follow that practice here, too, rather than risk failing to replicate the earlier findings by testing half the subjects with the light first.

2. Yeo (1974) did not perform this statistical contrast. However, it is possible to perform a Wilcoxon rank sums test on data presented in his Figure 3 and to show the difference to be significant ( $p=.05$, onetailed).

3. One study that found similar levels of freezing to tone and light CSs is that of Holland (1979b, Experiment 3). That study differed procedurally from the others cited in its use of relatively weak USs and relatively short test CSs.

(Manuscript received July 16, 1986; revision accepted for publication December $15,1986$. 